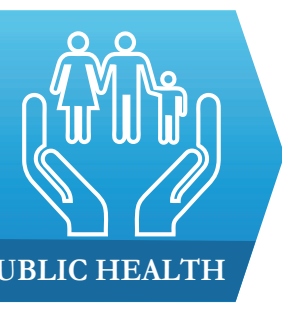

1) Department of Biomedical Science, Kulliyyah of Allied Health Sciences, International Islamic University Malaysia, Jalan Sultan Ahmad Shah, 25200 Kuantan, Pahang, Malaysia

2) Department of Physical Rehabilitation Sciences, Kulliyyah Of Allied Health Sciences, International Islamic University Malaysia, Jalan Sultan Ahmad Shah, 25200 Kuantan, Pahang, Malaysia

3) Unit of Pharmacology, Faculty of Medicine and Defence Health, Universiti Pertahanan National Malaysia (National Defence University of Malaysia), Kem Perdana Sungai Besi, 57000 Kuala Lumpur, Malaysia

DOI: $10.15386 / \mathrm{mpr}-1227$

Manuscript received: 05.11.2018

Received in revised form: 18.02.2019

Accepted: 12.03.2019

Address for correspondence:

runurono@gmail.com

\title{
Knowledge, attitude and practice regarding hypertension among residents in a housing area in Selangor, Malaysia
}

Nurul Fatin Binti Buang ${ }^{1}$, Nor Azlina A Rahman², Mainul Haque ${ }^{3}$

\begin{abstract}
Background and aims. Hypertension is becoming a global epidemic and threat to the world population. This cross-sectional study was carried out at a housing area in Selangor, Malaysia to study the knowledge, attitude and practice (KAP) regarding hypertension among the residents.

Methods. A total of 110 respondents aged 18 years old and above were selected by convenience sampling. Data was collected using a structured interviewer-guided questionnaire with Likert-scale choices of answers.

Results. All respondents were Malay with the mean age of 41 years [Standard Deviation $(\mathrm{SD})=11.828]$. The total mean and SD of knowledge, attitude and practice scores were $74.33(\mathrm{SD}=6.25), 44.22(\mathrm{SD}=5.05)$ and $27.55(\mathrm{SD}=2.86)$, respectively. There were significant positive correlations between knowledge with attitude $(\mathrm{r}=+0.393 ; \mathrm{p}<0.001)$ and practice $(\mathrm{r}=+0.378 ; \mathrm{p}<0.001)$. However, there was no significant correlation between attitude and practice $(\mathrm{r}=+0.120 ; \mathrm{p}=0.212)$. There were significant fair positive correlations between age with knowledge $(\mathrm{r}=+0.402 ; \mathrm{p}<0.001)$, attitude $(\mathrm{r}=+0.265$; $\mathrm{p}=0.005)$ and practice $(\mathrm{r}=+0.337 ; \mathrm{p}<0.001)$ regarding hypertension. Meanwhile, gender, educational level, employment status and family history had no significant association with knowledge, attitude and practice regarding hypertension.
\end{abstract}

Conclusion. This study revealed that KAP regarding hypertension were associated with age, but not with other socio-demographic characteristics studied. The awareness, prevention and control programs of hypertension in their community should be increased, so that the residents could enjoy and maintain the healthy lifestyle.

Keywords. healthy life style, cross-sectional studies, surveys and questionnaires, hypertension, Malaysia

\section{Introduction}

Hypertension is one of the most common chronic diseases and one of the most critical health problems causing death as single contributor in developed and developing countries [1,2]. In most cases of hypertension, the primary cause was not detected, and these cases are known as essential hypertension. Essential hypertension is not curable, but with medication the blood pressure (BP) can be controlled to that of the physiological level. Nevertheless, as hypertension itself usually does not present with symptoms, it can remain undiagnosed for a long time. Hypertension is also called as a silent killer disease, which is often diagnosed incidentally. If a hypertensive patient remains untreated, it can lead to serious life-threatening complications of vital organs such as the brain, eye, heart, and kidney, resulting in death or serious patient disability $[3,4]$. It is believed to be one of the main risk factors for peripheral vascular, cerebrovascular and cardiovascular diseases (CVD) which include stroke, coronary disease, peripheral artery disease, renal disease and heart failure [5,6]. Obesity, sedentary behaviors, and other individual risks for one of these cardiovascular illnesses could be increased by two to three times due to hypertension $[7,8]$.

The cost of antihypertensive medicine is very high and takes up a large and rising share of healthcare resources $[9,10]$. In Malaysia, hypertension is quite prevalent among adult and elderly population; the age-adjusted prevalence for 2007-2011 was 42.0\% (CI: 40.9-43.2), which was higher in males or overweight and obese people $[11,12]$. Its care is inadequate because the detection and treatment of hypertension 
is less than satisfactory $[13,14]$. High BP detection and control are seriously vital for decreasing the risk of strokes and heart attacks [15]. The prevalence of hypertension has not declined, although the enhancement in BP control is encouraging $[16,17]$. Nowadays, continuing health education in Malaysia through mass media is the results of good basic understanding on hypertension in the general population, while the limited detailed understanding indicates the urge to develop more specific health education programs. Moreover, limited motivation to implement healthy lifestyles indicates the urge to further develop an atmosphere conducive to healthy lifestyles [14].

There are some barriers to hypertension control, such as physician turn over, non-adherence to a fix protocol or guideline, prescribing antihypertensive drugs from one category or choosing two drugs from the same category as beta blockers, the side effects of combining several drugs inappropriately such as bradycardia, the cost of medications, and not having a fixed physician $[18,19]$. Besides, prescribed medication regimen for most hypertensive patients is not based on a standard protocol [18], thus the regimen is not effective for hypertension management and resulting in side effects and noncompliance [20,21]. It is necessary to focus more on education about hypertension and its management for physician and other related health care providers [22]. This problem ought to be highlighted as the prevalence of hypertension keeps increasing and will continue to worsen unless suitable preventive measures are implemented [23].

Several earlier studies conducted in Malaysia had emphasized that the prevalence of hypertension was high especially among rural community, where age and gender were the associated factors but not ethnicity [11,14,24,25]. Furthermore, hypertension was reported as a public health problem both in the rural and urban areas of Selangor $[11,14]$. In view of that, this study was carried out in a housing area in Selangor to see whether there are any similarities with the previous findings. The objectives of this study were to determine the knowledge, attitude and practice (KAP) regarding hypertension among residents in the housing area in Selangor, Malaysia, also to assess the correlation between the KAP and to find the factors associated with KAP regarding hypertension.

\section{Methods}

\section{Study design and area}

The cross-sectional descriptive and analytical study design was used to assess the KAP regarding hypertension among residents in a semi-urban housing area in Selangor, Malaysia.

\section{Study population}

The study included permanent residents of the housing area who had been living there for at least one year. For each house approached, only two people were interviewed to represent the house. This was to avoid redundancy and inconsistency of responses.

\section{Sampling method}

Convenience sampling was applied in this study. The respondents were recruited based on their accessibility during the data collection. This sampling method was chosen because of the limitation of time and cost.

\section{Inclusion criteria}

Permanent residents who had been living in the area for at least one year; age between 18-70 years old; Malay.

\section{Exclusion criteria}

Do not understand Malay or English languages; having history of hypertension; history of mental illness. Sample size: It was calculated using Power and Sample Size software version 3.0.43. The calculated sample size was 108 with the assumption that $\alpha=0.05$, power $=0.8$, $\mathrm{m}=1, \delta=6$ and $\sigma=15.64$. The standard deviation $(\sigma=15.64)$ was based on a previous study [18]. The total number of respondents chosen for this study was 119 after taking into consideration the $10 \%$ non-response rate. However, at the end of the research period, the total respondents were 110 .

\section{Research tool and data collection}

The data was collected in January 2014. A guided interview was carried out through a structured questionnaire. The interview was conducted in the local language (Malay) for the ease of communication between the researcher and the respondents.

\section{Ethical Committee approval}

The study was approved by the International Islamic University Malaysia Research Ethics Committee (IREC) [IIUM/305/14/11/2/IREC 185]. Prior to the interview, explanation about the study was given to the respondents and written informed consent was obtained from them. The participation of the respondents was voluntary, and they had the right to stop participating in this study at any time. They also had the right to not answer any question that made them feel uncomfortable. Their confidentiality was assured throughout the study.

\section{Questionnaire}

A set of KAP questionnaire was designed and prepared, which was later reviewed by the experts in this field of study. It was prepared in English and translated into Malay language to be used during data collection. The questionnaire was divided into four parts: Socio-demographic information of the respondents, also sections on knowledge, attitude and practice regarding hypertension. The first part on socio-demographic information of the respondents includes gender, age, marital status, educational level, employment status and family history of hypertension. This information was obtained to make comparisons between the individual groups of the study population on the KAP of hypertension. It was to determine the factors affecting the KAP of hypertension among the study population. The second part on knowledge regarding hypertension contained fourteen questions including about hypertension risk factors, diseases and conditions related to hypertension and the sources of hypertension information. The answer choices were 
'yes', 'no' and 'not sure'. The part on attitude and practice regarding hypertension and its prevention used Likert-scale type of questions: seven questions on attitude with 5 scales of 'strongly agree' to 'strongly disagree' twelve questions on practice with the choices of response of 'always', 'sometimes' and 'never'. A pilot study was conducted to assess the face validity of the research instrument in terms of its understandability. Answer from each question was scored accordingly and then summed-up for each part to get the total scores of KAP regarding hypertension for each individual respondents. The total score was used to determine the level of KAP regarding hypertension and its associated factors.

\section{Statistical analysis}

The data collected was analyzed using the Statistical Package for Social Science (SPSS) version 21.0, [IBM, Armonk, NY, United States of America]. Pearson correlation test was used to study the relationship between the KAP and also with age, while independent t-test was used to analyze the difference of the KAP between the different groups of socio-demographic characteristics.

\section{Results \\ Socio-demographic distribution}

The survey questionnaire on KAP regarding hypertension was completed by 110 respondents whom socio-demographic characteristics are summarized in Table I. More than half of the respondents were females with $59.1 \%$ (65) with the mean age of all respondents was $41 \pm 11.828$ years old. All respondents were Malay with majority $(77.3 \%, \mathrm{n}=85)$ were married. Among the respondents $50.0 \%$ (55) $47.3 \%(52)$ and $2.7 \%$ (3) had secondary, tertiary, and primary educational level respectively. Most (50.9\%, $\mathrm{n}=56)$ of the respondents were salary-employed and the rest $12.7 \%(n=14), 23.6 \%(n=26), 6.4 \%(n=7), 5.5 \%(n=6)$, and $0.9 \%(\mathrm{n}=1)$ were self-employed, housewives, students, pensioners and unemployed respectively. More than half of the respondents had family history of hypertension $(60.9 \%$; $\mathrm{n}=67$ ).

\section{Knowledge regarding hypertension}

The total mean and standard deviation of knowledge score was $74.33 \pm 6.25$ with a median of 75 and the minimum and maximum score was 57 and 84, respectively. Among respondents $63.6 \%$ (70) and $97.3 \%$ (107) knew that smoking and dietary habits are the risk factors of hypertension. Additionally, 37.3\% (41), 84.5\% (93) of the respondents knew that memory loss and heart disease are related to hypertension respectively. Nevertheless, $52.7 \%$ (58) respondents believed cancer was associated with hypertension.

Table I. Socio-demographic characteristics of respondents $(n=110)$.

\begin{tabular}{|c|c|c|c|}
\hline Characteristics & $\begin{array}{c}\text { Male }(n=45) \\
\text { No. }(\%)\end{array}$ & $\begin{array}{c}\text { Female }(n=65) \\
\text { No. }(\%)\end{array}$ & $\begin{array}{c}\text { Total }(n=110) \\
\text { No. }(\%)\end{array}$ \\
\hline Gender & 45 (40.9) & $65(59.1)$ & $110(100)$ \\
\hline $\begin{array}{l}\text { Race } \\
\text { Malay }\end{array}$ & 45 (40.9) & $65(59.1)$ & $110(100)$ \\
\hline $\begin{array}{l}\text { Marital Status } \\
\text { Single } \\
\text { Married }\end{array}$ & $\begin{array}{c}8(17.8) \\
37(82.2)\end{array}$ & $\begin{array}{l}17(26.2) \\
48(73.8)\end{array}$ & $\begin{array}{l}25(22.7) \\
85(77.3)\end{array}$ \\
\hline $\begin{array}{l}\text { Educational Level } \\
\text { Primary } \\
\text { Secondary } \\
\text { Tertiary }\end{array}$ & $\begin{array}{c}0(0.0) \\
20(44.4) \\
25(55.6)\end{array}$ & $\begin{array}{c}3(4.6) \\
35(53.8) \\
27(41.5)\end{array}$ & $\begin{array}{c}3(2.7) \\
55(50.0) \\
52(47.3)\end{array}$ \\
\hline $\begin{array}{l}\text { Employment Status } \\
\text { Salary-employed } \\
\text { Self-employed } \\
\text { Pensioner } \\
\text { Student } \\
\text { Housewife } \\
\text { Unemployed }\end{array}$ & $\begin{aligned} 28 & (62.2) \\
9 & (20.0) \\
6 & (13.3) \\
2 & (4.4) \\
0 & (0.0) \\
0 & (0.0)\end{aligned}$ & $\begin{aligned} 28 & (43.1) \\
5 & (7.7) \\
0 & (0.0) \\
5 & (7.7) \\
26 & (40.0) \\
1 & (1.5)\end{aligned}$ & $\begin{aligned} 56 & (50.9) \\
14 & (12.7) \\
6 & (5.5) \\
7 & (6.4) \\
26 & (23.6) \\
1 & (0.9)\end{aligned}$ \\
\hline $\begin{array}{l}\text { Family History of hypertension } \\
\text { Yes } \\
\text { No }\end{array}$ & $\begin{array}{l}23(51.1) \\
22(48.9)\end{array}$ & $\begin{array}{l}44(67.7) \\
21(32.3)\end{array}$ & $\begin{array}{l}67(60.9) \\
43(39.1)\end{array}$ \\
\hline
\end{tabular}


The majority $(89.1 \%, \mathrm{n}=98)$ of the respondents knew something about hypertension and 59.1\% (65) of them knew the physiological level of BP. The statement "Information about hypertension could be acquired from people such as family members, friends or doctors" had the highest $(96.4 \%, n=106)$ proportion of correct response, followed by "Information about hypertension could be acquired from media such as television, internet, newspaper or magazine" (90.9\%, $\mathrm{n}=100)$. Among 88.2\% (97), 90.0\% (99), and 60.0\% (66) of the respondents correctly opined that hypertension is a leading risk factor for many critical illnesses such as cardiovascular disease, stroke and renal failure; that the disease can be controlled; and diagnosis is made solely based on BP measurement, respectively. Almost half $48.2 \%$ (53) of the respondents opined that the prevalence of hypertension is more in urban than rural area. Furthermore, $82.7 \%$ (91) and $72.7 \%(80)$ of the respondents knew that obesity greatly elevates the risk of hypertension and that the prevalence of hypertension increases with age, respectively. Nevertheless, $40.0 \%$ (44) were not sure that prevalence of hypertension in female is higher compared to male. Among the respondents, $84.5 \%(\mathrm{n}=93)$ and $87.3 \%(\mathrm{n}=96)$ positively opined that the higher level of knowledge is associated with better attitude and better practice, respectively.

\section{Attitude regarding hypertension}

The total mean attitude score was $44.22 \pm 5.05$, with a median of 46 and the minimum and maximum attitude score were 20 and 48, respectively. Among the respondents, $95.5 \%$ (105) were worried about their health if they have hypertension. Nevertheless, $75.5 \%$ (83) of the respondents opined positively that they would check BP even if they do not have any symptoms and $70.9 \%$ (78) disagree that they won't go for routine medical check-up to check for their BP. Among the respondents, 95.5\% (105) agreed that BP check was very important for health and prevention of hypertension was very important and $87.3 \%$ (96) of them agreed that it was important to pay attention to their BP measurement if they were always under stress, while only $63.6 \%(70)$ agreed to do that if they were a smoker. Almost all of the respondents $(94.5 \%, \mathrm{n}=104)$ agreed that they would be less likely to develop hypertension in the future if they ate healthy food and had enough sleep per day.

\section{Practice regarding hypertension}

The total mean practice score was $27.55 \pm 2.86$ with a median of 28 and the minimum and maximum practice score were 21 and 35, respectively. Among the respondents, $40.0 \%$ (44) always had their yearly BP check, while $30.9 \%$ (34) of them did read about hypertension. Nonetheless, $43.6 \%$ (48), $48.2 \%$ (53), $83.6 \%$ (92), $50.0 \%$ (55) and $18.2 \%$ (20) of respondents were always on healthy diet, took some food supplements, consumed salty and cholesterol food, had enough sleep per day and exercised at least three times per week, respectively. Most $(64.5 \%, \mathrm{n}=71)$ of the respondents' daily work was under stress sometimes, while $82.7 \%$ (91) of them never smoked. None of the respondents ever drink alcohol and $29.1 \%$ (32) respondents always get advice from doctors or other health professionals about good dietary habits.

Correlation between $K A P$ regarding hypertension

The correlation is estimated through bivariate analysis model to explore the relationship between the KAP scores (Table II). Knowledge had significant fair positive correlation with attitude $(\mathrm{r}=+0.393 ; \mathrm{p}<0.001)$ and practice $(\mathrm{r}=+0.378 ; \mathrm{p}<0.001)$ regarding hypertension. However, there was no significant correlation between attitude and practice regarding hypertension $(\mathrm{r}=+0.120 ; \mathrm{p}=0.212)$.

Association between $\mathrm{KAP}$ scores regarding hypertension and socio-demographic characteristics

The total scores of KAP were used to be compared between different socio-demographic factors such as age, gender, educational level, employment status and family history of the respondents.

\section{Correlation between $\mathrm{KAP}$ scores regarding hypertension and age}

The correlation was estimated through bivariate analysis model to explore the relationship between age and the KAP scores regarding hypertension (Table III). There was a significant fair positive correlation between age and knowledge score $(\mathrm{r}=+0.402 ; \mathrm{p}<0.001)$ and between age and attitude score $(\mathrm{r}=+0.265 ; \mathrm{p}=0.005)$ regarding hypertension. There was also a significant fair positive correlation between age and practice score $(\mathrm{r}=+0.337 ; \mathrm{p}<0.001)$ regarding hypertension.

Table II. Correlations between knowledge, attitude and practice regarding hypertension using Pearson Correlation Test $(\mathrm{n}=110)$.

\begin{tabular}{|c|c|c|c|}
\hline Variables & $\boldsymbol{r}$-value & $\boldsymbol{p}$-value & Interpretation \\
\hline Knowledge and Attitude & +0.393 & $<0.001$ & Fair positive correlation \\
Knowledge and Practice & +0.378 & $<0.001$ & Fair positive correlation \\
Attitude and Practice & +0.120 & 0.212 & No correlation
\end{tabular}

Table III. Correlations between age with total scores of knowledge, attitude and practice regarding hypertension using Pearson Correlation Test $(n=110)$.

\begin{tabular}{|c|c|c|c|}
\hline Variables & $\boldsymbol{r}$-value & $\boldsymbol{p}$-value & Interpretation \\
\hline Age and Knowledge Score & +0.402 & $<0.001$ & Fair positive correlation \\
Age and Attitude Score & +0.265 & 0.005 & Fair positive correlation \\
Age and Practice Score & +0.337 & $<0.001$ & Fair positive correlation
\end{tabular}


Table IV. Comparison of total scores of knowledge, attitude and practice regarding hypertension between different sociodemographic factors using independent t-test $(\mathrm{n}=110)$.

\begin{tabular}{|c|c|c|c|c|c|c|c|}
\hline \multirow{2}{*}{ Groups being compared } & \multirow{2}{*}{$\mathbf{n}$} & \multicolumn{2}{|c|}{ Knowledge scores } & \multicolumn{2}{|c|}{ Attitude scores } & \multicolumn{2}{|c|}{ Practice scores } \\
\hline & & Mean (SD $\left.{ }^{a}\right)$ & $p$-value & Mean (SD') & $p$-value & Mean (SD) & $p$-value \\
\hline \multicolumn{8}{|l|}{ Gender: } \\
\hline Male & 45 & $74.3(6.89)$ & \multirow[t]{2}{*}{0.982} & $44.0(5.07)$ & \multirow[t]{2}{*}{0.737} & $27.1(2.87)$ & \multirow[t]{2}{*}{0.200} \\
\hline Female & 65 & $74.3(5.83)$ & & $44.4(5.07)$ & & $27.9(2.84)$ & \\
\hline \multicolumn{8}{|l|}{ Education Level: } \\
\hline Lowerb & 58 & $74.2(5.94)$ & \multirow[t]{2}{*}{0.785} & $44.4(5.43)$ & \multirow[t]{2}{*}{0.754} & $28.0(2.97)$ & \multirow[t]{2}{*}{0.097} \\
\hline Higherc & 52 & $74.5(6.64)$ & & $44.1(4.64)$ & & $27.1(2.68)$ & \\
\hline \multicolumn{8}{|l|}{ Employment: } \\
\hline Workingd & 70 & $74.8(6.02)$ & \multirow[t]{2}{*}{0.296} & $43.6(5.74)$ & \multirow[t]{2}{*}{0.071} & $27.3(2.32)$ & \multirow[t]{2}{*}{0.364} \\
\hline Non-workinge & 40 & $73.5(6.63)$ & & $45.2(3.36)$ & & $27.9(3.63)$ & \\
\hline \multicolumn{8}{|l|}{ FH of HPT $^{f}$} \\
\hline Yes & 67 & $74.3(6.91)$ & \multirow[t]{2}{*}{0.977} & $44.3(4.80)$ & \multirow[t]{2}{*}{0.806} & $27.5(2.83)$ & \multirow[t]{2}{*}{0.884} \\
\hline No & 43 & $74.4(5.15)$ & & $44.1(5.48)$ & & $27.6(2.94)$ & \\
\hline $\begin{array}{l}\text { aStandard deviation; } \\
\text { dRespondents with salary }\end{array}$ & \multicolumn{7}{|c|}{$\begin{array}{l}\text { bPrimary and secondary education; } \quad \text { 'Tertiary education; } \\
\text { self-employed; } \quad \text { ePensioners, students, housewives and unemployed; }\end{array}$} \\
\hline
\end{tabular}

Comparing KAP regarding hypertension between different genders, educational levels, employment status and family history of hypertension

Table IV shows the results of statistical analysis using independent t-test to compare the KAP regarding hypertension between males $(n=45)$ and females $(n=65)$; between lower and higher education, where lower education $(\mathrm{n}=58)$ included those with primary and secondary education, and higher education $(\mathrm{n}=52)$ included those with tertiary education; between working and non-working respondents, where working respondents $(n=70)$ included those who were with salary and also self-employed, while the non-working respondents $(\mathrm{n}=40)$ included the pensioners, students, housewives and unemployed respondents; and also between those with family history of hypertension $(\mathrm{n}=67)$ and with no family history of hypertension $(\mathrm{n}=43)$. All the p-values were more than 0.05 , between 0.071 to 0.982 , indicating that there were no significant differences in KAP regarding hypertension between the groups being compared (Table IV).

\section{Discussion}

Hypertension has become a significant problem in many developing countries experiencing epidemiological transition from communicable to non-communicable chronic diseases [26,27]. Therefore, hypertension is a silent secret threat to the health of people around the world. As the BP rises, the risk of stroke and coronary heart disease also increases [13]. Cardiovascular disease is expected to become a major concern in developing countries. It is also an important cause of worldwide preventable morbidity and mortality. The two major manifestations of cardiovascular diseases are coronary heart disease and stroke. Hypertension is one of the most common risk factors for cardiovascular diseases in adults [28].

\section{Socio-demographic characteristics}

The majority of the respondents were female because it was mostly women who were available at home during the time of interview. Most of the respondents were employed, married with the age range of 26-55 years old. A proportion of the respondents was younger, with the age range of 18-25 years. They were most probably students who were living with their parents. The rest of the respondents were older pensioners with the age range of 56-70 years. The respondents who had been interviewed were all Malays which represent the majority of the residents of the study area. Half of the respondents had only up to the secondary level of education, probably because the portion of respondents were older and did not have the same chance to further education as the current younger generation. Those with higher educational level were expected to have better level of KAP regarding hypertension. Quite a number of the respondents were housewives, probably because they were the ones available at their houses and responsible to look after their families and houses daily. Hypertension is quite prevalent in Malaysia [13], which is supported by the fact that more than half of the respondents had family history of hypertension. This finding was similar to the results of another earlier study [28].

\section{$K A P$ regarding hypertension}

Hypertension is the most common chronic disease and one of the most crucial health problems worldwide [29]. Ignorance regarding this disease can lead to bad attitude and might dangerously direct to the core of the rising hypertension prevalence as the effect of poor practice of healthy diet and lifestyle $[18,30]$. The results from this study show that knowledge of the respondents regarding hypertension was good. This might be because almost all of the respondents got much information about hypertension from various sources, such as other people and media. This result was similar to an earlier study [31]. Mass media and 
friends are the most common sources that contributed most to the knowledge on various aspects of hypertension among their subjects. However, this information is inconsistent with the result from another earlier study [32]. The low score of knowledge was mainly due to low socio-economic class and illiteracy of the subjects.

According to the responses of the respondents' in this study, the areas where majority of the respondents could answer correctly were regarding the hypertension risk factors and the diseases associated with hypertension. More than 60 percent of the respondents knew about hypertension risk factors. Their answers were consistent with the result of a previous study [33]. Meanwhile, some of the respondents showed lack of knowledge regarding the prevalence of hypertension. More than half of the respondents did not know that prevalence of hypertension in urban area is higher compared to rural area as evidenced from a previous study [34]. Our study also found that about three quarters of the respondents did not know that prevalence of hypertension in male is higher compared to female as found in another previous study [35]. It is important to know the prevalence of hypertension, so that prevention steps could be taken in controlling the disease.

Cigarette smoking is also known as one of the risk factors for hypertension because smoking causes acute BP elevation, which can lead to other complications that weaken the function of the heart. Regardless of the fact, some of the respondents were yet to realize about this, thereby only $63.6 \%$ answered this correctly when asked about hypertension risk factors. This result is correlated to a study that found $90 \%$ of the respondents' opined smoking causes hypertension [33].

The respondents in this study were found to have excellent attitude towards preventing hypertension as they opined that although there is no symptom, they must check their BP regularly. Almost all of them also agreed that prevention of hypertension is very important. This result is supported by a previous study [18]. In the practice section, more than half of the items got poor performance of results which were below $50 \%$ of good practice. This is consistent with another study that found $73.2 \%$ of the subjects had poor score of practice regarding hypertension [32]. The low score of practice could be because of lack of motivation towards healthy lifestyles among the respondents. The score for exercising at least three times per week was low (18.2\%). This finding conveys the lack of activity involving body movement in the daily life of the subjects.

On the other hand, only $43.6 \%$ of the respondents were on healthy diet. These situations were likely results in lesser calories burnt up and in the long run it would affect the diet pattern of people, causing obesity and later, hypertension. Hypertension risk factors such as poor dietary habits including uncontrollable salty and cholesterol food intake would increase the prevalence of hypertension [36]. This factor as well as others such as smoking, diabetes mellitus and stress are known as modifiable risk factors. The result from this study is supported by a previous study which reported that most patients believed that salty diet, obesity and smoking were important factors in hypertension [37]. The same study mentioned that physical activity and exercise were very important factors in hypertension management [37].

\section{Correlation between $K A P$ regarding hypertension}

There was a significant but fair positive relationship between the total knowledge and attitude score, and between the total knowledge and practice score regarding hypertension. Based on the correlation between knowledge and attitude regarding hypertension among the respondents, it was found that higher knowledge contributed to the better attitude. This result implied that someone who knew more about hypertension had better attitude towards prevention of hypertension. It is consistent with the result from the study which found a significant correlation between attitude and practice regarding hypertension among the study population [18]. This explains that besides knowledge, those who had better attitude would also have better practice towards hypertension.

Next, fair positive correlation was also found between knowledge and practice regarding hypertension among the respondents. Better knowledge leads to better practice in some ways. As for example, someone who knew that habitual alcohol intake was associated with a higher blood pressure would stop drinking alcohol. Nonetheless, for someone who thought that habitual alcohol intake is not one of the risk factors of hypertension would drink alcohol excessively. However, there was no significant correlation between attitude and practice regarding hypertension in this study population. This indicated that the level of practices would not likely to be increased even when their attitude was better. As for example, majority of the respondents who agreed that they have responsibility to check their blood pressure yearly might not do so and do nothing to prevent hypertension. This was inconsistent with the result from another study which found a significant correlation between attitude and practice regarding hypertension among their study population, which explained that those who had better attitude would also have better practice towards hypertension [18].

Correlation between $\mathrm{KAP}$ regarding hypertension with socio-demographic characteristics

The current study found correlation between age and KAP regarding hypertension among the study population were at a good level. Interestingly, there was a significant fair positive correlation between age and KAP score regarding hypertension. This means that as the age increases, the KAP of the respondents towards hypertension also increases. The only factor which affects the KAP regarding hypertension in this study is age. Age was found to be the determinant of knowledge regarding hypertension. Younger adults had lower level of knowledge compared to the older respondents. This result was inconsistent with the finding another study 
reported that nearly $29 \%$ of respondents older than 65 years had lower knowledge about hypertension, compared with $18 \%$ of those ages $45-65$ and $22 \%$ of those younger than 45 [38]. There were no other socio-demographic factors which were significantly associated with the KAP regarding hypertension among the study population. All factors such as gender, educational level, employment status and family history that were tested in this study did not show any association with KAP regarding hypertension.

Hypertension risk factors such as smoking, diabetes mellitus, diet and stress are known modifiable risk factors, whereas age, male sex and positive family history are nonmodifiable risk factors [36]. A combination of risk factors has been shown to increase the risk as well as subsequent occurrence of cardiovascular diseases. In Malaysia, several studies have also highlighted that, prevalence of hypertension increases with increasing age in both genders $[11,13,14]$. The prevalence of hypertension in subjects aged 15 years or older was $27.8 \%$ and it was more prevalent in males compared to females $[13,39]$. The prevalence of hypertension among subjects aged 30 years or older had risen from $32.9 \%$ to $40.5 \%$ in 1996 to 2004, respectively. The odds of having hypertension raised with age, in subjects with a family history of hypertension, with rising body mass index, with declining levels of education, in males and in non-smokers had been explained by multivariate logistic regression [39].

One earlier study reported that out of 340 hypertensive patients, $38.52 \%$ patients had a family history of hypertension [32]. A family history of elevated blood pressure is one of the strongest risk factors for future development of hypertension in individuals [40]. Epidemiological studies suggest that $20-60 \%$ of essential hypertension is inherited and remaining is acquired or environmental $[41,42]$. Their results also suggested that exposure to factors that were implicated in the causation of hypertension was more common in deprived areas. There had been strong influence of lower educational levels and low income on poor hypertension outcomes as evidenced by lack of relevant knowledge required to maintain a quality hypertension control.

The prevalence of hypertension in age-standardized subjects was $35.8 \%$ in men and $25.0 \%$ in women aged 25 to 64 years, while $43.9 \%$ in men and $32.8 \%$ in women aged 35 to 64 years [33]. Age- and gender-adjusted rates of hypertension were higher in men, older, obese, black persons and persons with high serum cholesterol levels $[43,44]$. Regarding categories of socioeconomic status, the age, gender and ethnic group-adjusted rates of hypertension were higher in persons owning a car and in those without paid work [45-47].

\section{Limitations of the study an recommendation}

This is a cross-sectional which limits the causal inference of the results. Furthermore, the convenience sampling used cannot ensure the generalization of the results to the study population. In view of that, a cohort or experimental study with proper random sampling is recommended for better conclusion of the study results.

\section{Conclusion}

This study found an acceptable level of KAP regarding hypertension among the study respondents. There were also significant positive correlations between knowledge with attitude and practice regarding hypertension, which means that better knowledge will improve the attitude and practice of the respondents. There were also significant positive correlations between age of the respondents with their KAP regarding hypertension, though all other studied socio-demographic characteristics showed no similar association. Further effective health education programs need to be carried out to improve the awareness and knowledge of the community regarding this disease so that further complications of this disease can be prevented.

\section{References}

1. Bromfield S, Muntner P. High blood pressure: the leading global burden of disease risk factor and the need for worldwide prevention programs. Curr Hypertens Rep. 2013;15:134-136.

2. Ezzati M, Lopez AD, Rodgers A, Vander Hoorn S, Murray CJ; Comparative Risk Assessment Collaborating Group. Selected major risk factors and global and regional burden of disease. Lancet. 2002;360:1347-1360.

3. Iadecola C, Davisson RL. Hypertension and cerebrovascular dysfunction. Cell Metab. 2008;7:476-484.

4. Mensah GA, Croft JB, Giles WH. The heart, kidney, and brain as target organs in hypertension. Cardiol Clin. 2002;20:225-247.

5. Arboix A. Cardiovascular risk factors for acute stroke: Risk profiles in the different subtypes of ischemic stroke. World J Clin Cases. 2015;3:418-429.

6. Grenon SM, Vittinghoff E, Owens CD, Conte MS, Whooley $\mathrm{M}$, Cohen BE. Peripheral artery disease and risk of cardiovascular events in patients with coronary artery disease: insights from the Heart and Soul Study. Vasc Med. 2013;18:176-184.

7. Warren TY, Barry V, Hooker SP, Sui X, Church TS, Blair SN. Sedentary behaviors increase risk of cardiovascular disease mortality in men. Med Sci Sports Exerc. 2010;42:879-885.

8. Akil L, Ahmad HA. Relationships between obesity and cardiovascular diseases in four southern states and Colorado. $\mathrm{J}$ Health Care Poor Underserved. 2011;22(4 Suppl):61-72.

9. Barik D, Arokiasamy P. Rising Health Expenditure Due to Non-Communicable Diseases in India: An Outlook. Front Public Health. 2016;4:268.

10. Thorpe KE. The rise in health care spending and what to do about it. Health Aff (Millwood). 2005;24:1436-1445.

11. Abdul-Razak S, DaherAM, RamliAS, Ariffin F, Mazapuspavina MY, Ambigga KS, et al. Prevalence, awareness, treatment, control and socio demographic determinants of hypertension in Malaysian adults. BMC Public Health. 2016;16:351.

12. Eshkoor SA, Hamid TA, Shahar S, Ng CK, Mun CY. Factors Affecting Hypertension among the Malaysian Elderly. J Cardiovas Dev Dis. 2016;3(1).

13. Alefan Q, Ibrahim MIM, Razak TA, Ayub A. Cost of treating hypertension in Malaysia. Asian J Pharm Clin Res. 2009; 2:1-5.

14. Naing C, Yeoh PN, Wai VN, Win NN, Kuan LP, Aung K. 
Hypertension in Malaysia: An Analysis of Trends from the National Surveys 1996 to 2011. Medicine. 2016;95:e2417.

15. National Heart, Lung, and Blood Institute. High Blood Pressure Also known as Hypertension. 2018. Available at https:// www.nhlbi.nih.gov/health-topics/high-blood-pressure.

16. Gudmundsdottir H, Høieggen A, Stenehjem A, Waldum B, Os I. Hypertension in women: latest findings and clinical implications. Ther Adv Chronic Dis. 2012;3:137-146.

17. Banerjee S, Mukherjee TK, Basu S. Prevalence, awareness, and control of hypertension in the slums of Kolkata. Indian Heart J. 2016;68:286-294.

18. Sabouhi F, Babaee S, Naji H, Zadeh AH. Knowledge, awareness, attitudes and practice about hypertension in hypertensive patients referring to public health care centers in Khoor \& Biabanak. Iran J Nurs Midwifery Res. 2011;16:34-40.

19. Jarari N, Rao N, Peela JR, Ellafi KA, Shakila S, Said AR, et al. A review on prescribing patterns of antihypertensive drugs. Clin Hypertens. 2016;22:7.

20. Ramli A, Ahmad NS, Paraidathathu T. Medication adherence among hypertensive patients of primary health clinics in Malaysia. Patient Prefer Adherence. 2012;6:613-622.

21. Wang PS, Bohn RL, Knight E, Glynn RJ, Mogun H, Avorn J. Noncompliance with antihypertensive medications: the impact of depressive symptoms and psychosocial factors. J Gen Intern Med. 2002; 17:504-511.

22. Khosravi AR, Shirani S, Shahrokhi S, Mohammadifard N, Ansari R. Antihypertensive drugs used by hypertensive patients in the provincial cities of Isfahan, Najafabad and Arak. ARYA Atherosclerosis Journal. 2006;1:275-280.

23. Campbell NR, Petrella R, Kaczorowski J. Public education on hypertension: A new initiative to improve the prevention, treatment and control of hypertension in Canada. Can J Cardiol. 2006;22:599-600.

24. Yunus AM, Sherina M, Nor Afiah M, Rampal L, Tiew Kh. Prevalence of cardiovascular risk factors in a rural community in Mukim Dengkil, Selangor. Malays J Nutr. 2004;10:5-11.

25. Sumarni Mohd G, Muhammad Amir K, Ibrahim Md S, Mohd Rodi I, Izzuna Mudla MG, Nurziyana I. Obesity among schoolchildren in Kuala Selangor: a cross-sectional study. Trop Biomed. 2006;23:148-154.

26. Boutayeb A, Boutayeb S. The burden of non-communicable diseases in developing countries. Int J Equity Health. 2005;4:2.

27. Omoleke SA. Chronic non-communicable disease as a new epidemic in Africa: focus on The Gambia. Pan Afr Med J. 2013; $14: 87$.

28. Muhamad R, Yahya R, Harmy Mohamed Yusoff HM, Rao BS, Rao D. Knowledge, attitude and practice on cardiovascular disease among women in North-Eastcoast Malaysia. Int $\mathrm{J}$ of Collaborative Res Intern Med Public Health. 2012;4:84-98.

29. Verdecchia P, Porcellati C, Schillaci G, Borgioni C, Ciucci A, Battistelli M, et al. Ambulatory blood pressure. An independent predictor of prognosis in essential hypertension. Hypertension. 1994;24:793-801.

30. Buda ES, Hanfore LK, Fite RO, Buda AS. Lifestyle modification practice and associated factors among diagnosed hypertensive patients in selected hospitals, South Ethiopia. Clin Hypertens. 2017;23:26.

31. Akter R, Assadi R, Singh H, Abaszadhezouri MG, Lamichhane S, Ahadi H, Mathew E, Muttappallymyalil J, Gopakumar A. Sources of information and level of knowledge on hypertension among entry level university students in Ajman, UAE. Am J Res
Communicat. 2014;2:16-27.

32. Mahajan H, Kazi Y, Sharma B, Velhal GD. Assessment of KAP, risk factors and associated co-morbidities in hypertensive patients. IOSR J Dent Med Sci. 2012;1:6-14.

33. Aubert L, Bovet P, Gervasoni JP, Rwebogora A, Waeber B, Paccaud F. Knowledge, attitudes, and practices on hypertension in a country in epidemiological transition. Hypertension. 1998;31:1136-1145.

34. Chow CK, Teo KK, Rangarajan S, Islam S, Gupta R, Avezum $A$, et al. Prevalence, awareness, treatment, and control of hypertension in rural and urban communities in high-, middleand low-income countries. JAMA. 2013;310:959-968.

35. Cappuccio FP, Micah FB, Emmett L, Kerry SM, Antwi S, Martin-Peprah R, et al. Prevalence, detection, management and control of hypertension in Ashanti, West Africa. Hypertension. 2004;43:1017-1022.

36. Wood D, De Backer G, Faergeman O, Graham I, Mancia G, Pyörälä K. Task force report. Prevention of coronary heart disease in clinical practice. Summary of recommendations of the Second Joint Task Force of European and other Societies on Coronary Prevention. Blood Press. 1998;7:262-269.

37. Kokubo Y. Prevention of hypertension and cardiovascular diseases: A comparison of lifestyle factors in Westerners and East Asians. Hypertension. 2014;63:655-660.

38. Viera AJ, Cohen LW, Mitchell CM, Sloane PD. High blood pressure knowledge among primary care patients with known hypertension: A North Carolina Family Medicine Research Network (NC-FM-RN) study. J Am Board Fam Med. 2008;21:300-308.

39. Rampal L, Rampal S, Azhar MZ, Rahman AR. Prevalence, awareness, treatment and control of hypertension in Malaysia: a national study of 16,440 subjects. Public Health. 2008;122:11-18. 40. Ranasinghe P, Cooray DN, Jayawardena R, Katulanda P. The influence of family history of hypertension on disease prevalence and associated metabolic risk factors among Sri Lankan adults. BMC Public Health. 2015; 15:576.

41. Sarkar T, Singh NP. Epidemiology and Genetics of Hypertension. J Assoc Physicians India. 2015;63:61-98.

42. Srivastava K, Narang R, Bhatia J, Saluja D. Expression of Heat Shock Protein 70 Gene and Its Correlation with Inflammatory Markers in Essential Hypertension. PLoS One. 2016;11:e0151060. 43. Gao Y, Chen G, Tian H, Lin L, Lu J, Weng J, et al. Prevalence of hypertension in China: a cross-sectional study. PLoS One. 2013;8:e65938.

44. Félix-Redondo FJ, Grau M, Fernández-Bergés D. Cholesterol and cardiovascular disease in the elderly. Facts and gaps. Aging Dis. 2013;4:154-169.

45. Tareque MI, Koshio A, Tiedt AD, Hasegawa T. Are the rates of hypertension and diabetes higher in people from lower socioeconomic status in Bangladesh? Results from a nationally representative survey. PLoS One. 2015;10: e0127954.

46. Kaczmarek M, Stawińska-Witoszyńska B, Krzyżaniak A, Krzywińska-Wiewiorowska M, Siwińska A. Who is at higher risk of hypertension? Socioeconomic status differences in blood pressure among Polish adolescents: a population-based ADOPOLNOR study. Eur J Pediatr. 2015;174:1461-1473.

47. Rawshani A, Svensson AM, Rosengren A, Eliasson B, Gudbjörnsdottir S. Impact of Socioeconomic Status on Cardiovascular Disease and Mortality in 24,947 Individuals with Type 1 Diabetes. Diabetes Care. 2015;38:1518-1527. 